JHR

36,5

898

Received 13 January 2021

Revised 22 April 2021

Accepted 11 May 2021

\section{Building a resilient public health system for international migrant workers: a case study and policy brief for COVID-19 and beyond}

\author{
Chanapong Rojanaworarit
}

Department of Health Professions, School of Health Professions and Human Services, Hofstra University, Hempstead, New York, USA, and

Sarah El Bouzaidi

Master of Public Health Program, Hofstra University, Hempstead, New York, USA

\begin{abstract}
Purpose - This article analyzes deficiencies in public health services for international migrant workers (IMWs) during the COVID-19 pandemic and provides a policy brief for improvement of the public health system.

Design/methodology/approach - A COVID-19 outbreak that initially clustered in IMWs and further contributed to the resurgence of the disease across Thailand in December 2020 was analyzed to address the deficiencies in public health services based on the framework of the 10 Essential Public Health Services (EPHS). The EPHS framework was also applied to develop policy options and recommendations in the subsequent policy brief.

Findings - This outbreak unveiled unique challenges that make IMWs more vulnerable to COVID-19. The public health system, challenged by the COVID-19 outbreak among IMWs, manifested deficiencies in the planning and implementation of all essential services. Delayed detection of the outbreak along with the lack of policy accommodating undocumented IMWs and the lack of equitable access to testing and treatment for COVID-19 resulted in the transmission of the disease that harmed the public at large.

Originality/value - The comprehensive analysis of the deficiencies in public health services for IMWs enabled a clear description of problems that could be further prioritized by relevant stakeholders. The policy brief provides policymakers with evidence-based recommendations for improving public health services for IMWs during the COVID-19 pandemic and beyond.
\end{abstract}

Keywords COVID-19, International migrant workers, Disease outbreak, Vulnerable population,

Public health policy

Paper type Review

\section{Introduction}

International migrant workers (IMWs) are the backbone of the economy in many countries. In Thailand, an estimated 3,005,376 IMWs have been granted work permits in 2019 [1]. However, a large latent population remains undocumented. Of those who are documented, many work in manufacturing, construction, wholesale and retail, accommodation and food services, as well as agriculture, forestry and fishing [1]. As with any industry, the health of its workforce reflects its productivity [2]. Therefore, it is critical to provide adequate and equitable health and social services to all workers.

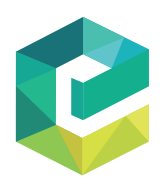

Journal of Health Research Vol. 36 No. 5,2022 pp. 898-907

Emerald Publishing Limited e-ISSN: 2586-940X p-ISSN: 0857-4421
(C) Chanapong Rojanaworarit and Sarah El Bouzaidi. Published in Journal of Health Research. Published by Emerald Publishing Limited. This article is published under the Creative Commons Attribution (CC BY 4.0) licence. Anyone may reproduce, distribute, translate and create derivative works of this article (for both commercial and non-commercial purposes), subject to full attribution to the original publication and authors. The full terms of this licence may be seen at http://creativecommons.org/licences/by/4.0/ legalcode

Funding: The authors received no financial support for the research, authorship, and publication of this article. 
Nonetheless, IMWs, particularly those who are undocumented, face unique social challenges to maintaining good health and well-being within their host countries. For instance, they experience tight living conditions, language barriers, and limited access to health care [3]. The social vulnerabilities experienced within this population interact with COVID-19, exacerbating the effect of this infectious disease among IMWs. Thailand's COVID-19 outbreak among IMWs during late 2020 is an example of this phenomenon [4]. This COVID-19 outbreak raised concern about care for IMWs, exposed existing deficiencies in public health planning and serves as a catalyst for building a more resilient public health system.

This article aims to analyze the deficiencies in public health services for IMWs during the COVID-19 pandemic, using the outbreak of COVID-19 among IMWs in Thailand as a case study. It further generates informed policy recommendations that can be used to improve public health services for IMWs during the COVID-19 pandemic and in the future.

\section{Method of analysis}

A cluster of 2,629 COVID-19 cases detected among IMWs in Thailand during the period between December 20 and 27, 2021 was critically analyzed to assess potential sources of disease exposure and to identify challenges in disease control and prevention among IMWs. The deficiencies in public health services for IMWs were then investigated and addressed using the 10 Essential Public Health Services (EPHS) as a framework [5]. The EPHS framework was also applied to the development of policy options and recommendations in the subsequent policy brief.

\section{Lessons learned and policy brief}

\section{Situation analysis of COVID-19 resurgence in Thailand}

Thailand was the second country to confirm a COVID-19 case after China on January 13, 2020 $[4,6]$. However, the response this upper-middle-income country took to successfully manage the spread of COVID-19 was exemplary. Thailand's success has been rooted in its participatory approach, which emphasizes engagement, inclusivity, and shared responsibility among all people - e.g. universal mask wearing in public [7-9]. Thailand's universal healthcare coverage for its citizens ensures free testing and treatment for COVID-19 to contain all cases within hospitals. This limits risk of transmission from infected individuals to their communities. Nevertheless, the country faced a new challenge. A cluster of 2,629 COVID-19 cases was identified among IMWs - many of whom are undocumented - in a large shrimp market in the province of Samut Sakhon between December 20 and 27, 2020 [4]. This cluster has been linked to the spread of disease in 44 provinces - over half the country. This outbreak provides testimony that IMWs, particularly those undocumented, are at heightened risk for COVID-19 [10, 11]. The outbreak also illustrates the need to improve care for IMWs during and long after the COVID-19 pandemic.

\section{Unveiling challenges for COVID-19 control and prevention in IMWs}

This outbreak unveils unique challenges that make IMWs more vulnerable to COVID-19 than other populations. Before becoming migrant workers, some of these individuals face deprivations including educational and economic hardship, which drive them to leave their home country [12]. Others even risk their lives to enter their host country illegally. Once employed, they experience another set of challenges. Low daily wages restrict them to living in tightly packed rooms with other occupants, which compromises social distancing and facilitates the transmission of COVID-19. With limited health literacy and income, IMWs lack an adequate understanding about the importance of personal protective equipment (PPE) 
JHR

36,5

900

and are hesitant to spend money on items like masks when resources can be used for rent, food or remittance.

While Thailand has strived to engage and include everyone in its COVID-19 control and prevention campaigns, public communication about COVID-19 is rarely in a language these workers understand. Language barriers perpetuate poor health literacy and poor COVID-19 outcomes [13]. If IMWs contract COVID-19, they continue to encounter other barriers such as reluctance to leave the job for testing or treatment due to loss of daily wage. Unlike documented IMWs, undocumented IMWs lack the right to access healthcare [14]. Undocumented workers also tend to distrust authorities due to a fear of deportation [15, 16]. As a result of these barriers, infected workers are left undetected and untreated. Since $90 \%$ of infected workers are asymptomatic, they further spread COVID-19 to their contacts at the shrimp market. This resulted in this newly emerging outbreak across Thailand.

\section{Addressing deficiencies in COVID-19 public health services for IMWs}

The deficiencies in all ten essential public health services for IMWs were identified using the EPHS framework (Table 1). The deficiencies identified can be simplified into three core functions: assessment, policy development and assurance [5].

Within the assessment, the public health system failed to address the vulnerabilities of IMWs during the COVID-19 pandemic. The system further lacked active surveillance to proactively identify cases of disease among IMWs. Once the outbreak was recognized, the system struggled with providing COVID-19 testing and treatment to IMWs. This lack of preparedness limited the effectiveness of disease containment to the local area.

Regarding policy development, the existing laws penalizing undocumented workers have created a hostile environment, which makes collaboration between IMWs and all acting authorities challenging to achieve [10]. The lack of mutual understanding and inability to effectively communicate due to language barriers further complicates cooperation between these stakeholders. This urges the need for public health systems to develop a more diverse and integrative workforce that builds trust, fosters relationships and gains cooperation among IMW communities and authorities [17]. Even after collaboration is achieved, public health systems still face challenges providing COVID-19 testing and other services to IMWs, especially those who are undocumented.

With regards to assurance, the public health system lacked preparedness in providing additional testing and health services to IMWs. Expanding these services that are available to the general population to cover IMWs, particularly those who are undocumented, would improve the public health system as a whole. Apart from the unavailability of services, public health systems need to integrate IMWs into the workforce by mobilizing existing groups -i.e. migrant worker health volunteers. To better serve IMWs, public health systems should also improve research regarding social inequities within this vulnerable population. This could further allow public health systems to better anticipate IMWs needs and social vulnerabilities to provide early interventions that improve care for IMWs [18].

\section{Policy alternatives and recommendations}

To build a more resilient public health system, existing deficiencies in public health services must be resolved through policy and system reform (Table 1). This starts with improving the assessment of health status among IMWs, the development of appropriate policies and the assurance of effective and sustainable delivery of public health services.

The assessment of vulnerabilities and factors influencing the overall health of IMWs is critical for developing a prevention-oriented health system that limits potential future outbreaks from occurring. Nonetheless, if an outbreak occurs, the surveillance system should function to timely detect the event [19]. Awareness of the outbreak etiology would further 


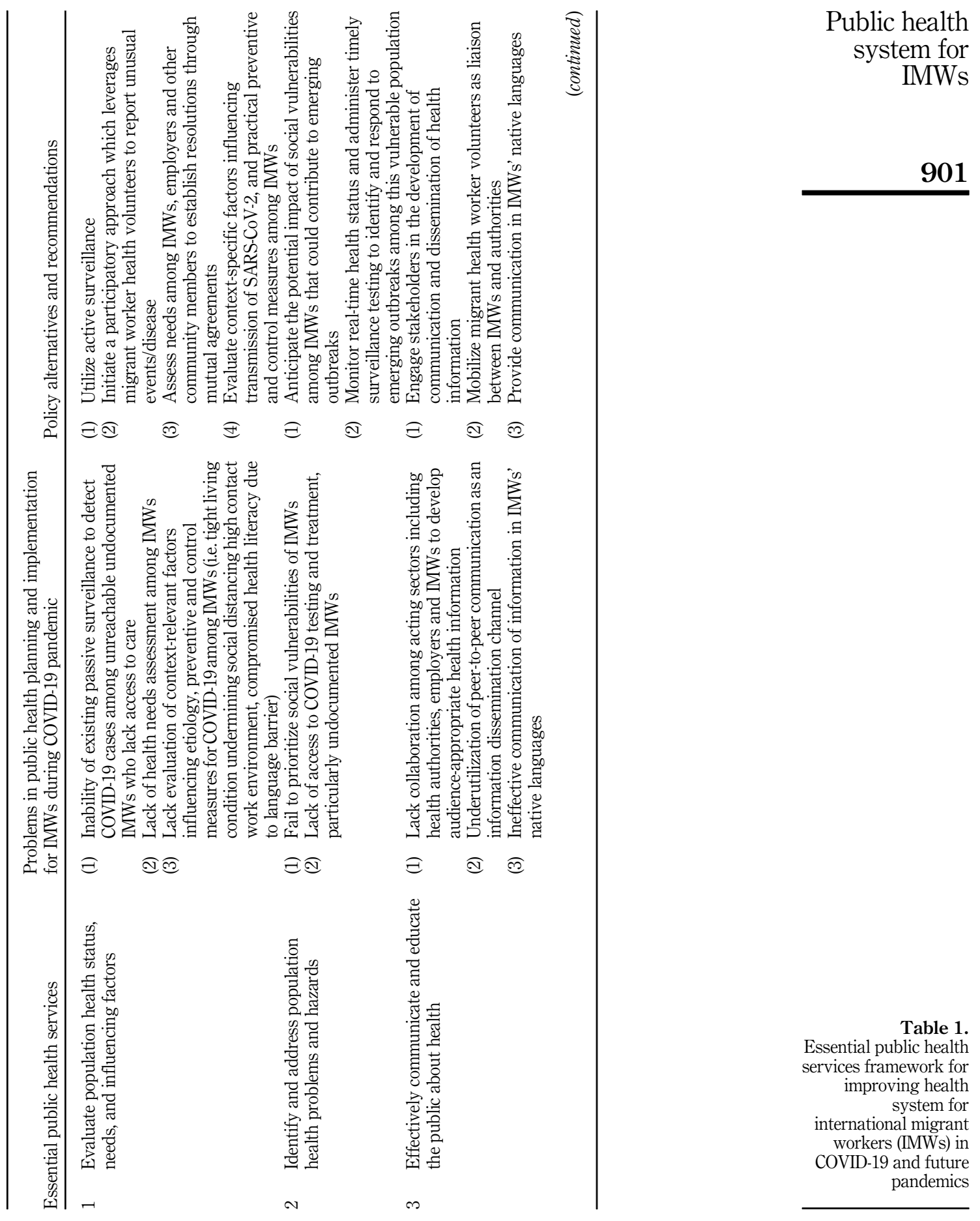


JHR
36,5

902

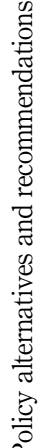

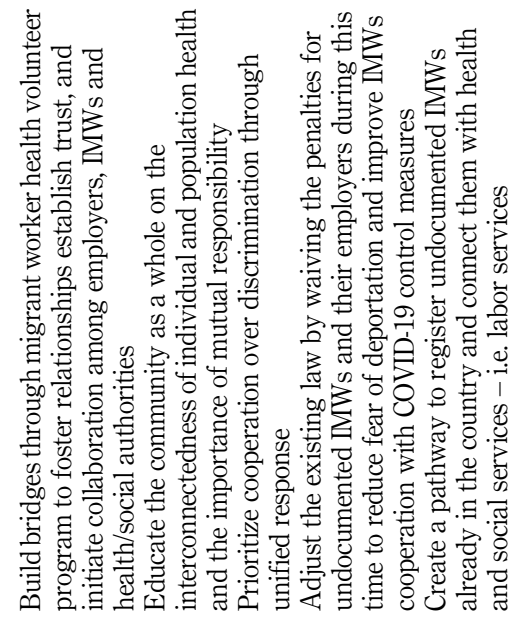

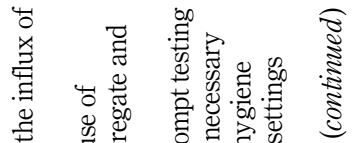

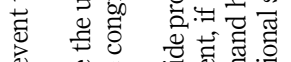

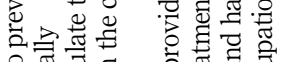
我范

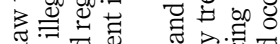

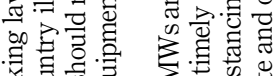

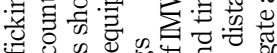

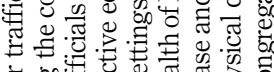

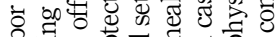

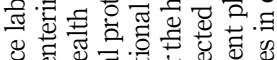

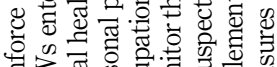

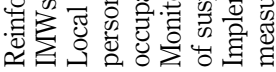
Ð
ฮิ
ลำ
ชิ
ฮิ $\widehat{ } \oplus$

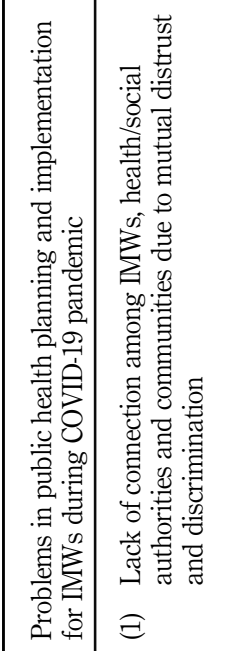

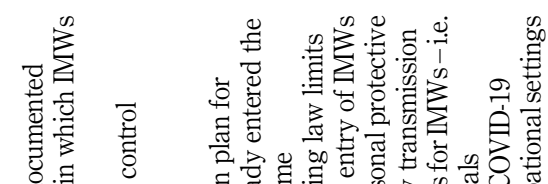

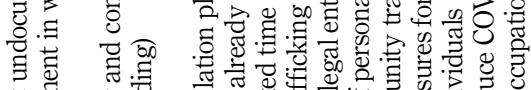

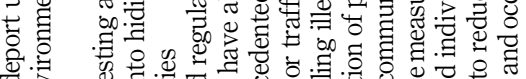

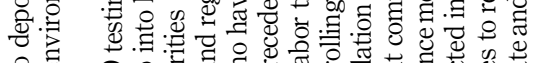

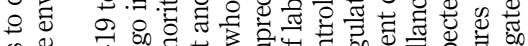

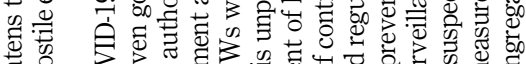

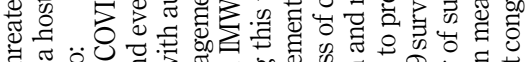

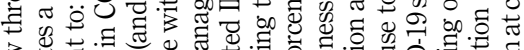

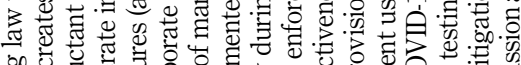
of

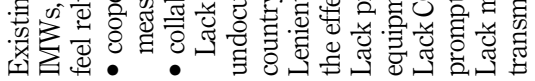

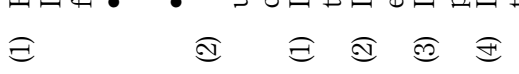

Table 1.

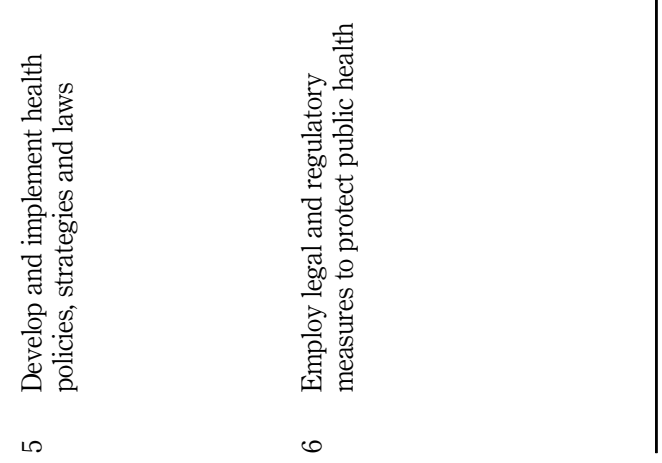




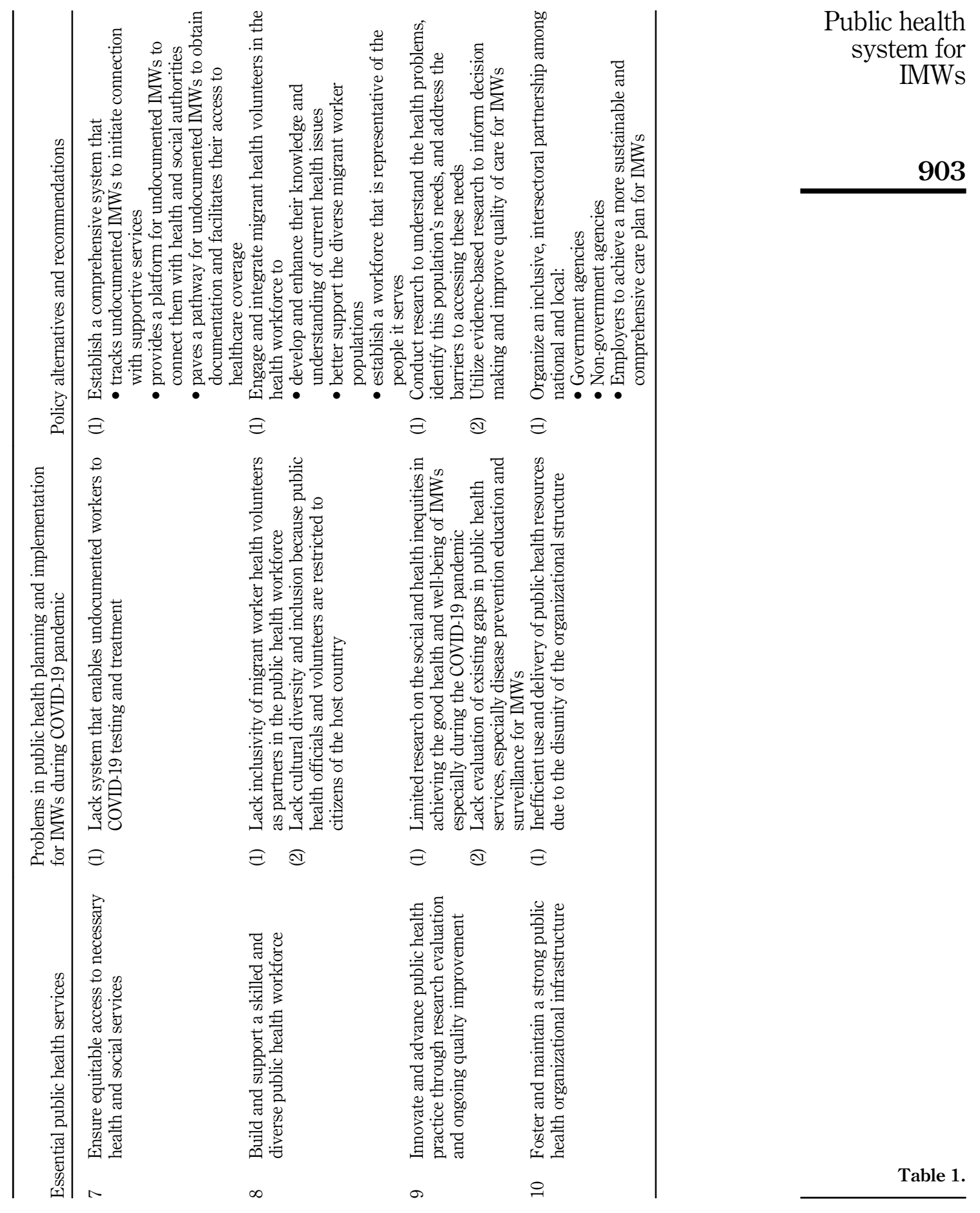


JHR

36,5

904

allow systems to contain the disease at an early stage. To achieve timely detection, authorities should conduct active case finding and cooperate with IMWs. To overcome potential barriers in collaboration - i.e. distrust, language barriers, and poor health literacy - between IMWs and authorities, public health systems should engage IMWs as a part of the public health workforce. The migrant worker health volunteer program recruits volunteers from IMWs to facilitate that collaboration [20]. Since migrant worker health volunteers tend to be wellintegrated in IMW communities, they can participate in active case finding by reporting unusual events and diseases to health authorities. Apart from facilitating the disease surveillance, volunteers also bridge further communication and deliver health messages to improve health literacy using IMWs' native languages to encourage cooperation for further disease control measures - i.e. COVID-19 testing and quarantine [21].

Collaboration between IMWs, authorities and other stakeholders is also important for improving the development of inclusive policies. To protect IMWs, especially those who are undocumented, the system should acknowledge the vulnerabilities of IMWs and be adaptive to accommodate these vulnerabilities. Furthermore, the system should integrate individuals from multiple sectors to ensure a skilled and diverse workforce [22]. Public health systems should also be self-regulatory and provide essential services at their best, regardless of an individual's immigration status or healthcare coverage [23]. Once the policy is developed and implemented, it is necessary to assure that the policy is working as intended. To achieve quality and sustainable care for IMWs, health systems should actively engage in research, innovation, and quality assurance.

Health system reform must commence at the core ideology that IMWs are a burden on the health systems of their host country. This notion drives stigmatization and xenophobia which further creates a hostile environment for the host communities and IMWs [24-26]. To alleviate the hostile environment, the public health system should cooperate with legal authorities to be adaptive by waiving the existing law that penalizes undocumented IMWs and their employers [10]. Establishing an inclusive and empathetic environment through partnerships and public health campaigns is essential. These public health campaigns should inform and educate members of the host communities on the importance of mutual understanding and acceptance of individuals from different social backgrounds, particularly highlighting the notion that they all are members of a larger community that must work together to achieve effective control and prevention of the disease. To provide further support, IMWs must be connected with social and health authorities through the facilitation of migrant worker health volunteers [20].

Apart from accommodating existing IMWs, there is a need to prevent the incidence of illegal entry of IMWs into the host country. The poor regulation of labor trafficking laws is the root cause for becoming an undocumented IMW. Trafficked workers are imposed to human rights violations including infringements upon their right to healthcare. As a result, labor trafficking laws must be reinforced and individuals involved in importing migrant workers illegally must be prosecuted [27].

The lack of COVID-19 testing and treatment for undocumented IMWs is a key factor that heightens the transmission of disease within this vulnerable population. Therefore, providing COVID-19 testing and necessary treatment to IMWs is essential for controlling outbreaks within communities. However, in the long run, providing COVID-19 testing and treatment can consume resources within the health system of the host country. Even countries with universal healthcare coverage like Thailand face challenges in providing sustainable services to undocumented IMWs. While Thailand provides healthcare benefits to documented IMWs, these essential services do not cover undocumented IMWs. Expansion of this coverage to undocumented IMW is controversial and can further strain healthcare resources [14].

Intersectoral collaboration to engage multiple stakeholders including members of government and non-government agencies, employers and IMWs can enable a more 
sustainable and comprehensive care plan for IMWs. For the case of Thailand, key government agencies including the Ministry of Defense, the Ministry of Labor, the Ministry of Public health collaborate to initiate a pathway for undocumented IMWs to have essential healthcare benefits in the long run. The Ministry of Defense provides IMWs who have entered the country illegally a two-year amnesty period for them to enroll in the registration of the Ministry of Labor. The Ministry of Labor further assists IMWs by connecting those who are unemployed with employers who are willing to hire and sponsor them. Once they are sponsored and registered by the Ministry of Labor, these IMWs become documented. This allows them to utilize the copayment system and receive healthcare benefits [28].

To further assure quality care for IMWs during and after the COVID-19 pandemic, ongoing needs assessments will be necessary to address their health needs and to better serve IMWs. Providing disease prevention services to all individuals including this vulnerable population would protect the health of the population at large [4]. Research conducted to identify the social inequalities of IMWs could also identify areas that need improvements. Long-term engagement of IMWs in the public health workforce will be key in building a supportive environment, establishing mutual understanding and promoting solidarity necessary to protect the community from the existing health threats and future pandemics.

\section{Conclusions}

Resilient public health systems must be comprised of the five foundational components: awareness, diversity, integration, adaptability and self-regulation [29]. A resilient public health system for IMWs should timely detect the emerging health threats through appropriate surveillance strategies and provide channels for prompt disease diagnosis and treatment. The system should also be adaptive to effectively respond to unprecedented situations. To successfully protect the health of the public at large, public health systems should integrate diverse stakeholders in the workforce and promote intersectoral collaboration. The function of the public health system at its best should be self-regulatory.

Conflicts of Interest: None

\section{References}

1. Thailand, Ministry of Labour. Labour statistics yearbook 2019. Bangkok: Office of Permanent Secretary; 2019.

2. Mitchell RJ, Ozminkowski RJ, Serxner S. Improving employee productivity through improved health. J Occup Environ Med. 2013; 55(10): 1142-8. doi: 10.1097/JOM.0b013e3182a50037.

3. Norredam M, Agyemang C. Tackling the health challenges of international migrant workers. Lancet Glob Health. 2019; 7(7): e813-4. doi: 10.1016/s2214-109x(19)30224-4.

4. Rojanaworarit C, El Bouzaidi S. International labour trafficking: a neglected social origin of COVID-19. Lancet Reg Health West Pac. 2021; 8: 100121. doi: 10.1016/j.lanwpc.2021.100121.

5. Centers for Disease Control and Prevention. 10 essential public health services. [cited $2021 \mathrm{Apr}$ 21]. Available from: https://www.cdc.gov/publichealthgateway/publichealthservices/ essentialhealthservices.html.

6. Phucharoen C, Sangkaew N, Stosic K. The characteristics of COVID-19 transmission from case to high-risk contact, a statistical analysis from contact tracing data. EClinicalMedicine. 2020; 27: 100543. doi: 10.1016/j.eclinm.2020.100543.

7. Issac A, Radhakrishnan RV, Vijay VR, Stephen S, Krishnan N, Jacob J, et al. An examination of Thailand's health care system and strategies during the management of the COVID-19 pandemic. J Glob Health. 2021; 11: 03002. doi: 10.7189/jogh.11.03002. 
JHR

36,5

906
8. Li T, Liu Y, Li M, Qian X, Dai SY. Mask or no mask for COVID-19: a public health and market study. PLoS One. 2020; 15(8): e0237691. doi: 10.1371/journal.pone.0237691.

9. Feng S, Shen C, Xia N, Song W, Fan M, Cowling BJ. Rational use of face masks in the COVID-19 pandemic. Lancet Respir Med. 2020; 8(5): 434-6. doi: 10.1016/s2213-2600(20)30134-x.

10. Bhopal R. Covid-19: undocumented migrants are probably at greatest risk. BMJ. 2020; 369: m1673. doi: 10.1136/bmj.m1673.

11. Page KR, Venkataramani M, Beyrer C, Polk S. Undocumented U.S. Immigrants and Covid-19. N Engl J Med. 2020; 382(21): e62. doi: 10.1056/NEJMp2005953.

12. Dumon W. Problems faced by migrants and their family members, particularly second generation migrants, in returning to and reintegrating into their countries of origin. Int Migr. 1986; 24(1): 113-28.

13. Khan S, Asif A, Jaffery AE. Language in a time of COVID-19: literacy bias ethnic minorities face during COVID-19 from online information in the UK. J Racial Ethn Health Disparities. 2020: 1-7. doi: 10.1007/s40615-020-00883-8.

14. Legido-Quigley H, Pocock N, Tan ST, Pajin L, Suphanchaimat R, Wickramage K, et al. Healthcare is not universal if undocumented migrants are excluded. BMJ. 2019; 366: 14160. doi: 10.1136/ bmj.14160.

15. Kerani RP, Kwakwa HA. Scaring undocumented immigrants is detrimental to public health. Am J Public Health. 2018; 108(9): 1165-6. doi: 10.2105/ajph.2018.304596.

16. Flynn MA, Eggerth DE, Jacobson CJ Jr. Undocumented status as a social determinant of occupational safety and health: the workers' perspective. Am J Ind Med. 2015; 58(11): 1127-37. doi: 10.1002/ajim.22531.

17. Mitchell DA, Lassiter SL. Addressing health care disparities and increasing workforce diversity: the next step for the dental, medical, and public health professions. Am J Public Health. 2006; 96(12): 2093-7. doi: 10.2105/ajph.2005.082818.

18. Ahmed F, Ahmed N, Pissarides C, Stiglitz J. Why inequality could spread COVID-19. Lancet Public Health. 2020; 5(5): e240. doi: 10.1016/s2468-2667(20)30085-2.

19. Rojanaworarit C. Principles of public health surveillance: a revisit to fundamental concepts. JPHD. 2015; 13(1): 69-86. doi: 10.14456/jphd.2015.2.

20. Kosiyaporn H, Julchoo S, Phaiyarom M, Sinam P, Kunpeuk W, Pudpong N, et al. Strengthening the migrant-friendliness of Thai health services through interpretation and cultural mediation: a system analysis. Glob Health Res Policy. 2020; 5(1): 53. doi: 10.1186/s41256-020-00181-0.

21. Kosiyaporn H, Julchoo S, Sinam P, Phaiyarom M, Kunpeuk W, Pudpong N, et al. Health literacy and its related determinants in migrant health workers and migrant health volunteers: a case study of Thailand, 2019. Int J Environ Res Public Health. 2020; 17(6). doi: 10.3390/ijerph17062105.

22. Raffoul M, Bartlett-Esquilant G, Phillips RL Jr. Recruiting and training a health professions workforce to meet the needs of tomorrow's health care system. Acad Med. 2019; 94(5): 651-5. doi: $10.1097 / \mathrm{acm} .0000000000002606$.

23. Richman LS, Lattanner MR. Self-regulatory processes underlying structural stigma and health. Soc Sci Med. 2014; 103: 94-100. doi: 10.1016/j.socscimed.2013.12.029.

24. Bhanot D, Singh T, Verma SK, Sharad S. Stigma and discrimination during COVID-19 pandemic. Front Public Health. 2020; 8: 577018. doi: 10.3389/fpubh.2020.577018.

25. Chopra KK, Arora VK. Covid-19 and social stigma: role of scientific community. Indian J Tuberc. 2020; 67(3): 284-5. doi: 10.1016/j.ijtb.2020.07.012.

26. Tuyisenge G, Goldenberg SM. COVID-19, structural racism, and migrant health in Canada. Lancet. 2021; 397(10275): 650-2. doi: 10.1016/s0140-6736(21)00215-4.

27. Kiss L, Zimmerman C. Human trafficking and labor exploitation: toward identifying, implementing, and evaluating effective responses. PLoS Med. 2019; 16(1): e1002740. doi: 10. 1371/journal.pmed.1002740. 
28. Tangcharoensathien V, Thwin AA, Patcharanarumol W. Implementing health insurance for migrants, Thailand. Bull World Health Organ. 2017; 95(2): 146-51. doi: 10.2471/blt.16.179606.

29. Kruk ME, Myers M, Varpilah ST, Dahn BT. What is a resilient health system? Lessons from Ebola. Lancet. 2015; 385(9980): 1910-2. doi: 10.1016/s0140-6736(15)60755-3.
Public health system for

IMWs

\section{Corresponding author}

Chanapong Rojanaworarit can be contacted at: Chanapong.Rojanaworarit@hofstra.edu 